\title{
Mechanical Properties of Neutron-Irradiated Model and Commercial FeCrAl Alloys
}

\author{
Kevin G. Field, ${ }^{1 *}$ Samuel A. Briggs, ${ }^{2}$ Kumar Sridharan, ${ }^{3}$ \\ Richard H. Howard, ${ }^{4}$ Yukinori Yamamoto ${ }^{5}$ \\ 1,4,5 Oak Ridge National Laboratory, Oak Ridge, TN 37831, USA \\ ${ }^{2,3}$ University of Wisconsin-Madison, Madison, WI 53706, USA \\ ${ }^{1}$ fieldkg@ornl.gov \\ ${ }^{2}$ sabriggs2@wisc.edu \\ ${ }^{3}$ kumar@engr.wisc.edu \\ ${ }^{4}$ howardrh@ornl.gov \\ 5 yamamotoy@ornl.gov
}

*Corresponding author:

Kevin G. Field

Materials Science and Technology Division

PO Box 2008

Oak Ridge, TN 37831 (USA)

Phone: +1 8652415623

Email: fieldkg@ornl.gov

${ }^{\dagger}$ This manuscript has been authored by UT-Battelle, LLC under Contract No. DE-AC05-00OR22725 with the U.S. Department of Energy. The United States Government retains and the publisher, by accepting the article for publication, acknowledges that the United States Government retains a non-exclusive, paid-up, irrevocable, world-wide license to publish or reproduce the published form of this manuscript, or allow others to do so, for United States Government purposes. The Department of Energy will provide public access to these results of federally sponsored research in accordance with the DOE Public Access Plan (http://energy.gov/downloads/doe-public-access-plan).

(C) 2016. This manuscript version is made available under the Elsevier user license http://www.elsevier.com/open-access/userlicense/1.0/ 


\title{
Mechanical Properties of Neutron-Irradiated Model and Commercial FeCrAl Alloys
}

\author{
Kevin G. Field, ${ }^{1 *}$ Samuel A. Briggs, ${ }^{2}$ Kumar Sridharan, ${ }^{3}$ \\ Richard H. Howard, ${ }^{4}$ Yukinori Yamamoto ${ }^{5}$ \\ 1,4,5 Oak Ridge National Laboratory, Oak Ridge, TN 37831, USA \\ ${ }^{2,3}$ University of Wisconsin-Madison, Madison, WI 53706, USA \\ ${ }^{1}$ fieldkg@ornl.gov \\ ${ }^{2}$ sabriggs2@wisc.edu \\ ${ }^{3}$ kumar@engr.wisc.edu \\ ${ }^{4}$ howardrh@ornl.gov \\ ${ }^{5}$ yamamotoy@ornl.gov
}

\begin{abstract}
The development and understanding of the mechanical properties of neutron-irradiated $\mathrm{FeCrAl}$ alloys is increasingly a critical need as these alloys continue to become more mature for nuclear reactor applications. This study focuses on the mechanical properties of model FeCrAl alloys and of a commercial $\mathrm{FeCrAl}$ alloy neutron-irradiated to up to 13.8 displacements per atom (dpa) at irradiation temperatures between 320 and $382^{\circ} \mathrm{C}$. Tensile tests were completed at room temperature and at $320^{\circ} \mathrm{C}$, and a subset of fractured tensile specimens was examined by scanning electron microscopy. Results showed typical radiation hardening and embrittlement indicative of high chromium ferritic alloys with strong chromium composition dependencies at lower doses. At and above $7.0 \mathrm{dpa}$, the mechanical properties saturated for both the commercial and model $\mathrm{FeCrAl}$ alloys, although brittle cleavage fracture was observed at the highest dose in the model $\mathrm{FeCrAl}$ alloy with the highest chromium content (18 wt \%). The results suggest the composition and microstructure of $\mathrm{FeCrAl}$ alloys plays a critical role in the mechanical response of $\mathrm{FeCrAl}$ alloys irradiated near temperatures relevant to light water reactors.
\end{abstract}

Keywords: FeCrAl, Accident Tolerant, Mechanical Properties

\footnotetext{
${ }^{\dagger}$ This manuscript has been authored by UT-Battelle, LLC under Contract No. DE-AC05-00OR22725 with the U.S. Department of Energy. The United States Government retains and the publisher, by accepting the article for publication, acknowledges that the United States Government retains a non-exclusive, paid-up, irrevocable, world-wide license to publish or reproduce the published form of this manuscript, or allow others to do so, for United States Government purposes. The Department of Energy will provide public access to these results of federally sponsored research in accordance with the DOE Public Access Plan (http://energy.gov/downloads/doe-public-access-plan).
} 


\section{Introduction}

Development of $\mathrm{FeCrAl}$ alloys for nuclear power applications was originally pursued by General Electric (GE) Corporation in the 1960s with the objective of developing oxidation-resistant fuel elements that would lead to better thermal efficiency, higher burnup, and robust containment of fission products in nuclear reactor environments of steam, air, and carbon-dioxide [1]. A significant amount of work was completed toward developing these alloys for high-temperature nuclear power applications, including studies of fuel-clad compatibility, high-temperature exposure in both air and steam, aging, welding/formability, and radiation effects, among several other topics [1-5]. Furthermore, development of both wrought and powder metallurgy processed $\mathrm{FeCrAl}$ alloys was pursued. Eventually, $\mathrm{FeCrAl}$ alloys lost favor in this high-temperature materials program, as the alloys developed at the time did not exhibit adequate high-temperature mechanical properties for structural applications [6] and were prone to embrittlement [4].

The original properties that made $\mathrm{FeCrAl}$ alloys attractive for use in high-temperature nuclear reactor applications are now also drawing attention to their development for accident-tolerant-fuel (ATF) applications [7]. FeCrAl alloys have shown outstanding high-temperature steam oxidation resistance [811], a key characteristic for developing systems with enhanced safety margins during design-basis and beyond-design-basis accident scenarios for light water reactor (LWR) cladding applications [12]. ATF applications such as LWR cladding would involve lower expected service temperatures than those studied by GE in considering FeCrAl alloys for use in high-temperature nuclear reactors. Lower operating temperatures and modern processing routes could overcome the deficiencies described within GE's alloy development program in the 1960s. Hence, $\mathrm{FeCrAl}$ alloys are currently undergoing rapid advancement. Of primary interest is developing an alloy or set of alloys that perform well in both pressurized water reactor and boiling water reactor environments during normal operation while exhibiting strong steam oxidation resistance during accident scenarios. Current efforts have shown a balance must be achieved between $\mathrm{FeCrAl}$ materials properties, including high-temperature mechanical strength, oxidation resistance, formability, thermal stability, creep strength, and radiation tolerance. 
Radiation tolerance assessment of $\mathrm{FeCrAl}$ alloys is of primary importance, as neutron radiation exposure can result in significant deviations in the mechanical properties of the material compared with as-received or even aged conditions. In high-chromium $(\mathrm{Cr})$ ferritic alloys, these deviations typically entail significant hardening and embrittlement and hence limit the service life in a nuclear reactor. As noted, the early high-temperature materials program completed several radiation tolerance evaluations, including irradiation at $50^{\circ} \mathrm{C}$ to a neutron fluence of $1 \times 10^{19} \mathrm{n} / \mathrm{cm}^{2}(\mathrm{E}>1 \mathrm{MeV})$ (dpa was not reported) of a FeCrAl alloy with 15 wt \% Cr. The alloy showed significant changes in the ductile-to-brittle transition temperature and radiation-induced hardening [5]. Building on this, Field et al. conducted mechanical tests on neutron-irradiated model $\mathrm{FeCrAl}$ alloys of varying compositions to $1.8 \mathrm{dpa}$ at $382^{\circ} \mathrm{C}$, which showed similar behavior with significant hardening and a composition dependence in the hardening driven by the formation of the Cr-rich $\alpha^{\prime}$ phase [13]. Additional work has been completed on commercial alloys, such as the study of Ahmedabadi and Was in which the Kanthal Advanced Power Metallurgy Technology (APMT) alloy was proton-irradiated to $5 \mathrm{dpa}$ at $360^{\circ} \mathrm{C}$ and tested using constant-extension-rate tensile tests; it demonstrated good stress corrosion cracking resistance and reduction of area [14]. Other than these studies, few details exist for the mechanical response of neutron- or ion-irradiated FeCrAl alloys.

Furthermore, little attention has been paid to whether the issues identified in the high-temperature materials program in the 1960 s have been remedied through modern design and fabrication processes. A critical need exists to develop a robust and expansive mechanical properties database on as-received and neutron-irradiated $\mathrm{FeCrAl}$ alloys before their deployment as an ATF technology in commercial LWRs.

In this study, investigations were performed to assess the mechanical properties of advanced oxidation-resistant $\mathrm{FeCrAl}$ alloys after neutron irradiation from beginning-of-life to expected near end-oflife dpa conditions at a nominal temperature of $320^{\circ} \mathrm{C}$ using accelerated testing in a materials test reactor. The same model alloys used in the previous study [13] and the powder metallurgy-derived, commercially available FeCrAl alloy Kanthal APMT were investigated. Tensile tests of sub-size tensile specimens and post-test fractography were used to determine key mechanical properties, including yield stress, tensile ductility, and reduction of area. The results and analysis within this study represent continuing steps 
toward developing a database of mechanical properties and radiation tolerance of $\mathrm{FeCrAl}$ alloys for nuclear power production applications, including LWR ATF cladding.

\section{Materials and Methods}

Materials for irradiation and subsequent tensile testing included four model FeCrAl alloys with varying $\mathrm{Cr}$ and aluminum additions and the commercially available $\mathrm{FeCrAl}$ alloy Kanthal APMT. The model alloys studied are designated as F1C5AY, B125Y, B154Y-2, B183Y-2 and have been the subject of several other studies as well [13,15-17]. In the case of the "B-series" alloys, the first two numbers in the alloy designation refers to the nominal target $\mathrm{Cr}$ composition while the third number refers to the nominal $\mathrm{Al}$ composition, e.g. B125Y has a nominal $\mathrm{Cr}$ content of $12 \mathrm{wt} . \%$ and $\mathrm{Al}$ content of 5 wt.\%. The F1C5AY model alloy had a nominal content of $10 \mathrm{wt} . \% \mathrm{Cr}$ and 5 wt.\% Al. The compositions of all alloys studied were determined using inductively coupled plasma optical emission spectroscopy (ICP-OES), the results of which are presented in Table 1.

Model FeCrAl alloys were manufactured using standard wrought alloy practices, including arc melting of pure element feedstocks and pre-alloyed aluminum-yttrium specimens. Thermomechanical treatments of the model $\mathrm{FeCrAl}$ alloys were conducted using hot forging, rolling, and heat treatment, according to conditions prescribed by Yamamoto et al. [12]. Ten percent cold-work was applied to the model alloys before final sample machining. The as-received microstructures of the model FeCrAl alloys were dominated by dislocation networking and dislocation cell structures [13]. Kanthal APMT, an alloy produced by powder metallurgy techniques including oxide dispersion, was studied alongside these wrought model $\mathrm{FeCrAl}$ alloys.

Details for the sample geometries and lower-dose irradiation conditions for the model alloys have been provided in previous work $[13,16,17]$. All specimens used in those studies and within this study were prepared by a single vendor using wire electric discharge machining to make dog-bone, sheet-type SS-J2 specimens (gage size $5.0 \times 1.2 \times 0.5 \mathrm{~mm}$ ). Six specimens per alloy were irradiated for each dosetemperature condition. Neutron irradiations were completed in the central flux trap of the High Flux 
Isotope Reactor (HFIR) from $0.3 \mathrm{dpa}$ to $13.8 \mathrm{dpa}$. Irradiations of capsules at $0.3 \mathrm{dpa}$ and $0.8 \mathrm{dpa}$ were completed using the hydraulic tube facility at HFIR; all other capsules were irradiated in static positions.

Neutron flux, and hence dose rate, varied depending on the axial locations of the capsules within the central flux trap of HFIR. Table 2 provides the details of each irradiation condition. Target irradiation temperatures were designed to be $320^{\circ} \mathrm{C}$. The temperatures shown in Table 2 were determined from performing dilatometric analysis of passive silicon carbide $(\mathrm{SiC})$ thermometry samples contained within each irradiation capsule. The dilatometric analysis was conducted up to a maximum temperature of $600^{\circ} \mathrm{C}$ at a constant ramp rate of $1^{\circ} \mathrm{C} / \mathrm{min}$ and a cooling rate of $2.5^{\circ} \mathrm{C} / \mathrm{min}$ using a Netzsch $402 \mathrm{CD}$ dilatometer. Analysis of individual specimens was completed using the methodology outlined by Campbell et al. [18]. The median temperature derived from the dilatometric analysis was used as the nominal irradiation temperature. Errors for the temperatures in Table 2 are reported as one standard deviation of the mean from at least three separate, randomly selected $\mathrm{SiC}$ thermometry specimens from the same irradiation capsule.

Tensile tests on the SS-J2 specimens in the as-received and irradiated state were performed on an Instron universal test machine. Tests were completed using shoulder loading with a crosshead speed of $0.0055 \mathrm{~mm} / \mathrm{s}$, resulting in a nominal strain rate of $\sim 10^{-3} \mathrm{~s}^{-1}$. Owing to the unavailability of a contact or non-contact extensometer at the time of the test, all engineering strains were determined from the digitally recorded crosshead separation. Engineering stress was calculated based on the digitally recorded load and measured thickness and width of the gage region before irradiation. Therefore, the calculations here assume negligible linear or volumetric swelling in the specimens due to neutron irradiation. This assumption seems within reason, as Little and Stow showed no swelling in a neutron-irradiated FeCrAl alloy near the temperatures studied here [19]. Room-temperature tests $\left(24^{\circ} \mathrm{C}\right)$ were performed in air, and high-temperature tensile tests $\left(320^{\circ} \mathrm{C}\right)$ were performed in high vacuum $\left(<1 \times 10^{-5}\right.$ torr $)$. Only a single hightemperature tensile test was performed per alloy for all irradiation conditions while several tests, especially for alloys irradiated to $1.8 \mathrm{dpa}$, were completed for many of the room temperature tensile tests. Where multiple specimens of the same alloy were tested for a single irradiation condition, the error is 
reported as one standard deviation of the mean of those tests. No post-irradiation surface preparation was performed before testing.

Fractured tensile surfaces of the F1C5AY, B183Y-2, and Kanthal APMT alloys were investigated using a remotely operated JEOL JSM-6010LA scanning electron microscope (SEM). A subset of alloy compositions was studied because of the time-intensive nature of the data acquisition and analysis. Non-

irradiated specimens were investigated using the same equipment and techniques. The SEM was operated at $5 \mathrm{kV}$ with a $10 \mathrm{~mm}$ working distance. When available, both halves of the fractured specimens were imaged in this manner. Reduction of area was measured from calibrated images of the fractured surfaces in the same manner used by Brachet et al. [20].

\section{Results}

\subsection{Unirradiated tensile properties}

Tensile curves for the $\mathrm{FeCrAl}$ alloys in the unirradiated condition tested at $24^{\circ} \mathrm{C}$ and $320^{\circ} \mathrm{C}$ are shown in Figure 1. No composition dependence between the model alloys in the unirradiated condition was observed. The model FeCrAl alloys showed nearly identical tensile behaviors to those reported by Yamamoto et al. for the yield strength, ultimate tensile strength, and uniform elongation tested at room temperature [12]. The magnitude of total elongation showed the largest deviations between this study and that of Yamamoto et al., although the trend of reduced total elongation ( 1-3\%) for tensile tests conducted at $320^{\circ} \mathrm{C}$ compared to room temperature tests is consistent. The deviation in the absolute values for total elongation in this study and that of Yamamoto et al. can be attributed to the differences in the test specimens used. For example, Gussev et al. and Byun et al. have shown strong dependencies between the thickness-to-width ratio and the reported total elongation values [21,22].

As noted by Yamamoto et al. and reinforced here, the model alloys with $10 \%$ cold working showed little to no uniform plastic deformation $(<1 \%)$, indicating the applied cold work eliminated any further significant increase in load carrying capacity after the initial yield in the alloys [12]. All model alloys failed in a ductile manner at room temperature and at $320^{\circ} \mathrm{C}$, as represented by the SEM-based fractography for the F1C5AY model alloy shown in Figure 2a-b. The reduction of area values for the 
F1C5AY and B183Y-2 alloys was determined to be $\sim 80 \%$ and $~ 90 \%$, respectively, in the unirradiated state, regardless of test temperature.

The Kanthal APMT alloy showed different behavior compared with the unirradiated model $\mathrm{FeCrAl}$ alloys. When tested at room temperature $\left(24^{\circ} \mathrm{C}\right)$, unirradiated Kanthal APMT showed brittle fracture with little plastic deformation $(\sim 2 \%)$. When tested at $320^{\circ} \mathrm{C}$, it showed remarkably different behavior (Figure 1). The alloy exhibited the highest degree of uniform plastic deformation of any alloy tested when it was tested at high temperature. Furthermore, it showed signs of dynamic strain aging, a result consistent with previous findings for different heats of Kanthal APMT [14,23,24]. Fracture surfaces in the specimens tested at room temperature showed trademark transgranular fracture with faceted textures and river markings (Figure 2c). This finding corresponds with the observed brittle fracture and slight plastic deformation shown in the tensile test data. Tensile tests at $320^{\circ} \mathrm{C}$ showed vastly different fracture surfaces with typical dimple surfaces indicative of ductile fracture (Figure 2d). The reduction of area for tests performed at $320^{\circ} \mathrm{C}$ was determined to be $49 \%$, whereas room-temperature tests showed no apparent reduction of area.

\subsection{Irradiated tensile properties}

Engineering stress-strain curves up to 13.8 dpa for the F1C5AY model alloy, provided in Figure 3a, show the typical radiation-induced hardening and embrittlement responses for all model FeCrAl alloys after irradiation to the conditions provided in Table 2. Both test temperatures shown in Figure $3 \mathrm{a}$ demonstrate increases in yield strength, which are correlated with a loss of ductility and reduction in load carrying capacity after the initial yield as the damage dose increases. Room-temperature tests typically showed higher yield strengths for all model alloys. At higher doses ( $>2 \mathrm{dpa}$ ), no additional load carrying capacity after the initial yield was available in any model FeCrAl alloy, regardless of tensile test temperature. It should be noted that the $1.8 \mathrm{dpa}$ irradiation condition had a significantly higher irradiation temperature $\left(382^{\circ} \mathrm{C}\right)$ compared to all other irradiation conditions $\left(320-355^{\circ} \mathrm{C}\right)$ and hence in Figure $3 \mathrm{a}$ and the resulting data for the alloys shows lower yield stresses in 1.8 dpa condition. 
The Kanthal APMT did not show the same dose trends as the model alloys, as seen in the engineering stress-strain curves for Kanthal APMT in Figure 3b. When tested at room temperature, the low-dose (<2 dpa) specimens had decreasing plastic deformation with increasing dose. At higher doses, the Kanthal APMT specimens began to fail in the elastic regime; the failure stress decreased with increasing dose and saturated at $7.0 \mathrm{dpa}$ at $320^{\circ} \mathrm{C}$.

High-temperature tensile testing of irradiated Kanthal APMT showed more favorable results with regard to ductility. Kanthal APMT specimens at all doses tested had distinct yielding, followed by plastic deformation with signs of dynamic strain aging when tested at $320^{\circ} \mathrm{C}$. A serrated flow indicative of dynamic strain aging was most prominent in the Kanthal APMT specimen irradiated to 7.0 dpa at $320^{\circ} \mathrm{C}$. The load carrying capacity after initial yielding was maintained in the irradiated Kanthal APMT specimens tested at $320^{\circ} \mathrm{C}$, unlike in the model alloys, resulting in significantly greater uniform elongation in the Kanthal APMT specimens irradiated at high doses. For doses $\geq 7$ dpa, the Kanthal APMT specimens showed nearly identical total elongation values to those of the model $\mathrm{FeCrAl}$ alloys. A comparison of the tensile properties among all investigated alloys is presented in Figure 4 for tensile tests performed at room temperature and in Figure 5 for tensile tests performed at $320^{\circ} \mathrm{C}$. Results from the unirradiated and the $1.8 \mathrm{dpa}, 382^{\circ} \mathrm{C}$ specimens tested at room temperature from a previous study [13] were incorporated into the larger data set presented in this study.

Several distinct trends can be derived from Figure 4 and Figure 5. As noted in a previous study on irradiated model FeCrAl alloys [13], and seen in this study as well, the model FeCrAl alloys demonstrate that increasing the $\mathrm{Cr}$ concentration from 10 to $18 \mathrm{wt} \%$ results in an increased strength in the material, regardless of tensile test temperature, when it is irradiated to below $2 \mathrm{dpa}$. Although the strength properties changes are consistent, the changes in ductility properties in the alloys irradiated below 2 dpa are shown to be more complex than the changes in the strength properties: the $12 \mathrm{wt} \% \mathrm{Cr}$ model alloy (B125Y) shows lower total elongation and uniform elongation than the $15 \mathrm{wt} \% \mathrm{Cr}$ model alloy (B154Y2) irradiated to $1.8 \mathrm{dpa}$ at $382^{\circ} \mathrm{C}$, while the higher tensile test temperature shows nearly identical ductility responses for alloys with $\mathrm{Cr}$ concentrations of $10-15 \mathrm{wt} \%$. For either case (room temperature or $320^{\circ} \mathrm{C}$ 
tensile test), the B183Y-2 model alloy shows the highest degree of radiation-induced hardening and embrittlement, as indicated by its having the largest increase in yield strength and greatest decrease in both uniform elongation and total elongation.

The strong composition dependencies shown in Figure 4 and Figure 5 for the model alloys irradiated to a low dose no longer existed when they were irradiated to doses $\geq 7.0 \mathrm{dpa}$. All of the model alloys had saturated mechanical properties and exhibited a loss of uniform elongation $(<1 \%)$ and saturation of total elongation at nearly $10 \%$ at both test temperatures. Yield strengths were nearly identical for all model alloys, with values approaching 800 MPa when they were tested at room temperature and $\sim 600 \mathrm{MPa}$ when they were tested at $320^{\circ} \mathrm{C}$. The only outlier from this response was the B183Y-2 alloy, as it failed in the elastic regime at $13.8 \mathrm{dpa}$ under tensile testing at room temperature.

Figure 6 and Figure 7 show typical SEM fractographs associated with room temperature and $320^{\circ} \mathrm{C}$ tensile tests, respectively. The model alloy with the lowest $\mathrm{Cr}$ content (F1C5AY) showed typical dimple ductile fracture when tested both at room temperature and at $320^{\circ} \mathrm{C}$, regardless of irradiation condition. The ductile fracture mode showed reasonable necking, indicating the fracture was not highly localized. The high-Cr alloy (B183Y-2) showed nearly identical responses to the low-Cr model alloy (F1C5AY) under tensile testing at $320^{\circ} \mathrm{C}$ (Figure 7d); but it showed brittle, transgranular cleavage fracture when irradiated to $13.8 \mathrm{dpa}$ at $320^{\circ} \mathrm{C}$ and tensile-tested at room temperature (Figure $6 \mathrm{~d}$ ). The brittle behavior in the B183Y-2 model alloy is a behavior similar to that of the commercial Kanthal APMT when tested at room temperature, as shown in Figure 6e-f. The Kanthal APMT showed brittle, transgranular cleavage, even in the unirradiated condition, when tested at room temperature, as indicated earlier. The Kanthal APMT did show reasonably good ductile behavior even when irradiated to the highest studied damage dose and tensile-tested at $320^{\circ} \mathrm{C}$ (Figure $7 \mathrm{e}-\mathrm{f}$ ).

The reduction of area was measured on the specimens in Figure 6 and Figure 7, using a technique similar to that presented by Brachet et al. [20]. Figure 8 summarizes the resulting quantification of reduction of area for the irradiated alloys. The tensile behavior described earlier is well represented in Figure 8. Figure $8 \mathrm{~b}$ indicates good reduction-of-area values (>30\%) for all alloys tested at elevated test 
temperatures, even to doses above $7 \mathrm{dpa}$. This result indicates that even though most FeCrAl alloys showed a reduction in uniform elongation after irradiation, at elevated temperatures, the alloys nonetheless retained a reasonable degree of deformability. Even though the results generally showed acceptable deformability, at room temperature, the B183Y-2 model alloy showed no reduction of area, a result indicative of the brittle fracture shown in Figure 6d; the same response was observed for all Kanthal APMT specimens tested at room temperature, regardless of irradiation dose.

\section{Discussion}

The observed changes in mechanical properties with neutron irradiation in the studied model and Kanthal APMT alloys were consistent with results of similar studies of other ferritic high-Cr (>10 wt.\%) FeCr alloys, such as MANET (Fe-10 wt \% Cr) and HT-9 (Fe-12 wt \% Cr). For example, Anderoglu et al. [25] compiled results for high- $\mathrm{Cr} \mathrm{FeCr}$ alloys after neutron irradiation at temperatures below $350^{\circ} \mathrm{C}$ and showed a steep increase in yield strengths with increasing dose below $10 \mathrm{dpa}$, and then a saturation of irradiation-induced hardening above $10 \mathrm{dpa}$. Similarly, the uniform elongation was shown to significantly drop below $10 \mathrm{dpa}$ and then saturate at $0.5 \%$ beyond $10 \mathrm{dpa}$ in these alloys.

In this study, similar deformation behavior is shown in Figure 4 and Figure 5, especially in the case of the model FeCrAl alloys studied. The only significant difference observed between the high-Cr $\mathrm{FeCr}$ and $\mathrm{FeCrAl}$ deformation behavior is the observed "hump" in the uniform elongation and total elongation plots in Figure 4 and Figure 5. This "hump" has been attributed to the annealing of dislocations introduced during the cold-working of the model FeCrAl alloys before irradiation [13]. For example, the F1C5AY alloy had a $57 \%$ reduction (from $6.3 \pm 1.0 \times 10^{13} \mathrm{~m}^{-2}$ to $2.7 \pm 0.9 \times 10^{13} \mathrm{~m}^{-2}$ ) in the line dislocation density between the unirradiated and the $1.8 \mathrm{dpa}$ at $382^{\circ} \mathrm{C}$ irradiation [13]. Similar reductions $(40-81 \%)$ in the line dislocation density were observed in the remaining model alloys. This effect would not be observed significantly for high-Cr FeCr alloys processed to the normalized and tempered condition. The recovery in the model alloys could also be a key reason for the additional load carrying capacity observed in the $1.8 \mathrm{dpa}$ at $382^{\circ} \mathrm{C}$ irradiation condition. The similar dose trends between high-Cr 
$\mathrm{FeCr}$ and $\mathrm{FeCrAl}$ alloys, particularly at doses above 2.0 dpa where the cold-worked condition of the unirradiated state of the model $\mathrm{FeCrAl}$ alloys has little impact on the deformation behavior, suggests similar, if not identical, mechanisms for irradiation-induced hardening and embrittlement.

Initial insights into the irradiation-induced hardening and embrittlement can be developed based on the material dependent trends observed in Figure 4 and Figure 5. The primary material dependent trend shown in these Figures, Cr composition dependencies in the change in yield strength, is more readily represented in Figure 9 which uses a bubble plot to show the change in yield strength as a function of both the alloy $\mathrm{Cr}$ content and the irradiation dose for both tensile test temperatures. Figure 9 readily illustrates the low dose $(<2 \mathrm{dpa})$ Cr composition dependence when tested at room temperature and even more prominently in the elevated temperature tests. At higher doses, the $\mathrm{Cr}$ composition effect is not a dominate feature for the mechanical properties at room temperature when experimental error is considered and the dependence becomes less significant at elevated temperature. The result is two distinctly different regimes in mechanical behavior are observed; the first being a strongly composition dependent regime at doses below $2 \mathrm{dpa}$ and the second is a weakly correlated regime at damage doses above $2 \mathrm{dpa}$. It should be noted due to the relatively poor fidelity in the damage doses studied, the transitional dose between these two regimes could exist anywhere between $1.8 \mathrm{dpa}$ and $7.0 \mathrm{dpa}$, and could vary significantly for irradiations conducted at higher or lower temperatures.

A previous study completed a full microstructural characterization on the model $\mathrm{FeCrAl}$ alloy specimens irradiated to 1.8 at $382^{\circ} \mathrm{C}$ and tested at room temperature to determine the underlying mechanisms for the Cr composition dependencies for the irradiation-induced hardening and embrittlement in $\mathrm{FeCrAl}$ alloys in the low dose regime [12]. It was concluded through use of a dispersed barrier hardening model that most of the hardening observed in this irradiation condition could be attributed to radiation-induced defects, including $a / 2\langle 111\rangle$ dislocation loops, $a\langle 100\rangle$ dislocation loops, black dot damage, and the $\mathrm{Cr}$-rich $\alpha^{\prime}$ phase observed by transmission electron microscopy and small angle-neutron scattering. However, it was noted non-visible defects such as small vacancy clusters could also contribute to the overall hardening response. The study also determined that the Cr-rich $\alpha^{\prime}$ phase, with substantially 
high number densities, dominated the overall hardening response. Finally, it concludes that, since Cr-rich $\alpha^{\prime}$ precipitation is sensitive to initial Cr composition [13,16,17], the composition-dependent hardening response at these conditions could be attributed to the Cr-rich $\alpha^{\prime}$ phase. Similar composition dependencies based on the $\alpha^{\prime}$ precipitation response under irradiation have been suggested by other studies of $\mathrm{FeCr}$ alloys irradiated to similar low dose ( $<5$ dpa) LWR relevant conditions [26-28]. It is therefore suggested the Cr composition dependencies and resulting irradiation-induced hardening and embrittlement observed in the low dose (<2 dpa) conditions near LWR relevant temperatures is primarily driven by $\mathrm{Cr}$-rich $\alpha^{\prime}$ phase formation for both high-Cr (>10 wt.\%) FeCr and FeCrAl alloys, although other features such as dislocation loop formation can by a role in the mechanical response as well.

It is interesting that the composition-dependent hardening response disappeared with increasing doses at and above $7 \mathrm{dpa}$ in the $\mathrm{FeCrAl}$ alloys, especially considering the experimental scatter in the data set and the spans of nearly $12 \mathrm{wt} \% \mathrm{Cr}$ between the lowest-Cr model $\mathrm{FeCrAl}$ alloy and the commercial Kanthal APMT. Edmondson et al. show that the model $\mathrm{FeCrAl}$ alloy specimens irradiated at 7.0 dpa in this study contained the $\mathrm{Cr}$-rich $\alpha^{\prime}$ phase and show that a strong $\mathrm{Cr}$ composition dependence remained at this dose for the precipitation of this phase [16]. This result, and the lower dose structure-property results for $\mathrm{FeCrAl}$ alloys, suggest by extrapolation that a composition dependency at higher dose should exist. Given that such dependencies on composition do not exist, it appears that at higher doses, either other microstructural features, such as dislocation loops, and/or changes in deformation mode, such as dislocation channeling transitioning toward twinning, are occurring. Unfortunately, a full characterization of microstructures irradiated at high dose ( $\geq 7.0 \mathrm{dpa})$, including dislocation loop analysis and studies of deformed microstructures, were not available at the time of this study due to the latent radioactivity of the high dose specimens.

Although microstructural information in the high dose irradiated specimens is unavailable, and hence conclusive factors for the lack of a composition-dependent hardening response at higher doses remains undetermined, it is possible some details could be inferred from $\mathrm{FeCr}$ alloys as they show similar mechanical performance across the same dose and temperature regime. Unfortunately, the loss of the 
composition-dependent hardening response has not been directly observed by other studies of FeCr alloys irradiated near $300^{\circ} \mathrm{C}$ [26-28]. The lack of any observation of composition-dependent hardening response in the $\mathrm{FeCr}$ alloys is most likely because the highest irradiation dose achieved in those studies was 5.5 dpa, although much of the data is centered around 1 dpa.

Some insight can be gained from the studies of Park et al [29] and Triki et al [30], who investigated the mechanical response of high-Cr ferritic alloys after long term thermal aging. Both studies indicate the dominating effect of the Cr-rich $\alpha^{\prime}$ phase on the mechanical response even at long aging times (>100 h), and suggest a transition in the deformation mode from deformation bands (e.g., dislocation channeling) to twinning. Both dislocation channeling and twinning have been observed in other $\mathrm{FeCr}$ alloys after neutron irradiation [31] to similar doses and temperatures investigated in the higher dose regime here, which would support the deformation modes observed by Park et al. and Triki et al. Clearly, further investigations centered on the microstructural analysis of strained specimens-including dislocation loops, dislocation channeling, and twinning observations - are needed to determine the variance between the mechanisms for deformation in the lower-dose and higher-dose regimes in $\mathrm{FeCrAl}$ alloys.

The pronounced difference in the mechanical response between the commercial Kanthal APMT and the model $\mathrm{FeCrAl}$ alloys is also of interest. In particular, is the observation of dynamic strain aging based on the observation of serrated flow. Figure 10 shows the severity of the serrated flow for each irradiation condition under tensile testing at $320^{\circ} \mathrm{C}$ for Kanthal APMT. This response is not unexpected. Table 1 shows significantly higher carbon and nitrogen content in Kanthal APMT compared with the model alloys (0.03 wt \% to $0.005 \mathrm{wt} \%$ for carbon, respectively; $0.0504 \mathrm{wt} \%$ and $0.0003-0.0011 \mathrm{wt} \%$ for nitrogen, respectively) and shows Kanthal APMT having a 2.77 wt $\%$ molybdenum addition. Trace impurities have been associated with interactions with mobile dislocations — - both pre-existing and irradiation-induced dislocations - leading to serrated flow due to continuous locking and unlocking of the dislocations; see [32] and references within. Additionally, the substitutional elements in Kanthal APMT, 
such as $\mathrm{Cr}$, and the addition of molybdenum have been shown to have an affinity for free carbon and nitrogen, giving rise to an increased propensity for dynamic strain aging [32].

Figure 10 shows the frequency and magnitude of the serrations was significantly minimized at the highest dose (13.8 dpa at $\left.341^{\circ} \mathrm{C}\right)$, especially compared with the lower-dose, 7.0 dpa condition. The loss of serrated flow after necking in the 7.0 dpa sample was consistent with the strain rate dependencies shown by Guria and Chairt for Kanthal APMT [24], as the strain rate can be significantly higher during necking than when the material is undergoing uniform plastic deformation. The effect of neutron radiation on dynamic strain aging and serrated flow has been investigated for other Fe-based alloys; see $[33,34]$ and references within. These studies show that with increasing neutron fluence (or dose in this case), the degree of serrated flow is reduced partly because the radiation-induced microstructure traps free trace impurities such as carbon and nitrogen, preventing their interaction with mobile dislocations. Some merit should also be given to the difference in irradiation temperature in regards to efficiency of trapping free impurities, hence the varying serration response with increasing dose from the unirradiated condition in Figure 10. In general, the reduced serrations in the highest dose condition in this study suggest consistency in regards to dose trend with previous studies [33,34].

It has been reported that the embrittlement of some nuclear-grade steels can be related to dynamic strain aging $[35,36]$. Such a relationship would suggest that the dynamic strain aging observed as serrated flow at an elevated testing temperature $\left(320^{\circ} \mathrm{C}\right)$, but not during room-temperature tests, could be promoting the drastically different mechanical properties at the two test temperatures observed in Kanthal APMT in this study. Further investigation into the relationship between dynamic strain aging and the temperature dependence of the mechanical properties in Kanthal APMT would be needed to fully establish such relationship. A full determination of the dependencies for dynamic strain aging in Kanthal APMT — and ultimately its effects on mechanical properties — would require a more systematic study focused on irradiation dose, irradiation temperature, test temperature, strain rate, and impurity concentrations. Such a study is beyond the scope of this work. 
$\mathrm{FeCrAl}$ alloys are being considered for ATF LWR cladding meaning they are targeted to directly replace zirconium-based alloys within commercial LWRs. The mechanical properties indicated within this work should thus be compared to those of zirconium-based alloys after irradiation to provide an engineering-scale indication in the applicability of using FeCrAl alloys as ATF LWR cladding. A wide range of studies have been performed on irradiation-hardening and embrittlement in zirconium-based claddings, for comparison to the FeCrAl results presented in this study, the work of Cockeram et al. [37] is considered. Cockeram et al. irradiated Zircaloy-2 and Zircaloy-4 in similar tensile specimen configurations, the only difference being the thickness was halved, within the HFIR up to damage doses of between 0.013 and $6.8 \mathrm{dpa}$ at $358 \pm 20^{\circ} \mathrm{C}$. Tensile tests were performed in a similar manner although only tests at room temperature were completed. The result is nearly identical experimental parameters (flux, dpa, specimen configuration/production, etc.) exist between the data presented in this study on $\mathrm{FeCrAl}$ and that of Cockeram et al. on Zircaloy.

Similarities in the FeCrAl mechanical properties and that of Zircaloy-2 and Zircaloy-4 after accelerated neutron irradiation near similar irradiation temperatures are apparent. When irradiated to 6.8 dpa at $358^{\circ} \mathrm{C}$ the zirconium-based alloys demonstrated yield strengths in the range of 450 to $600 \mathrm{MPa}$ and total elongation in the range of 5-15\% depending on whether the alloys were $\alpha$-or $\beta$-annealed [37]. Both the model and commercial $\mathrm{FeCrAl}$ alloys showed higher yield strengths after irradiation to similar conditions. Remarkably, if the $\mathrm{FeCrAl}$ alloys failed in a ductile manner total elongations fell within the data scatter band for irradiated Zircaloy. Furthermore, the low $\mathrm{Cr}(\leq 15 \mathrm{wt} . \%)$ model FeCrAl variants and Zircaloy, showed ductile dimple-cone fracture after irradiation near 7 dpa at LWR relevant temperatures. The mechanical properties presented in this study and that of Cockeram represent a relative best-case scenario as other corrosion-assisted embrittlement mechanisms are not considered.

Retained ductility has direct implications in the performance of cladding under operation especially when subjected to pellet-cladding mechanical interaction. The similar mechanical performance, especially in relation to ductility, between both alloy classes, the retained deformability in the lower $\mathrm{Cr}$ $\mathrm{FeCrAl}$ alloys indicated by the reduction-of-area results in Figure 8, and limited susceptibly of $\mathrm{FeCrAl}$ 
alloys to corrosion-assisted embrittlement [14,38,39] suggests the applicability of FeCrAl alloys as ATF

LWR cladding from the standpoint of tensile properties under irradiation. Other mechanical properties, such as thermal creep and irradiation creep, should be determined prior to conclusively determining commercial use of any FeCrAl alloy as ATF LWR cladding.

\section{Conclusions}

A combined mechanical testing and fracture surface investigation allowed for analysis of the mechanical response of neutron-irradiated model and commercial FeCrAl alloys near LWR-relevant temperatures. Based on the presented analysis, the following statements can be made:

- Generally, irradiated FeCrAl alloys exhibited radiation-induced hardening and embrittlement behavior consistent with that of $\mathrm{FeCr}$ ferritic alloys, including increased yield strength and reduction in ductility with increasing radiation dose (dpa) when irradiated up to 13.8 dpa near typical LWR temperatures.

- Radiation-induced hardening and embrittlement severity increased with the $\mathrm{Cr}$ content in model $\mathrm{FeCrAl}$ alloys at irradiation doses of up to $7.0 \mathrm{dpa}$. Composition dependencies were less pronounced as the alloys approached saturation in mechanical properties at and above 7.0 dpa.

- Brittle cleavage fracture was observed after room-temperature testing in the highest-Cr (18 wt.\%) model $\mathrm{FeCrAl}$ alloy when it was neutron irradiated to $13.8 \mathrm{dpa}$ at $341^{\circ} \mathrm{C}$. It resulted in zero reduction of area, whereas the lowest-Cr $(10 \mathrm{wt} . \%)$ model FeCrAl alloy failed in a ductile manner with reductions of area near $70-80 \%$ regardless of the irradiation or test conditions.

- Kanthal APMT showed the same saturation of mechanical properties above 7.0 dpa as the model $\mathrm{FeCrAl}$ alloys under tensile testing at $320^{\circ} \mathrm{C}$; but it showed brittle fracture when tested at room temperature, regardless of irradiation condition.

- APMT showed drastically different behaviors under tensile testing at room temperature compared with tests at $320^{\circ} \mathrm{C}$, an effect that can be attributed in part to dynamic strain aging in the alloy; dynamic strain aging was not seen in the model alloys. Neutron irradiation to $13.8 \mathrm{dpa}$ at $341^{\circ} \mathrm{C}$ significantly reduced the dynamic strain aging effect in APMT.

Based on these statements, it can be concluded that the composition and microstructure of $\mathrm{FeCrAl}$ alloys play a critical role in their mechanical response to neutron irradiation, and that lower-Cr-content variants are less susceptible to brittle fracture above 7.0 dpa when they are irradiated near LWR-relevant temperatures. Additionally, lower-Cr-content $\mathrm{FeCrAl}$ alloy variants maintain adequate mechanical 
performance in the context of tensile properties after neutron irradiation for ATF LWR cladding applications when compared to zirconium-based alloys.

\section{Acknowledgments}

The authors would like to thank the Irradiated Materials Examination and Testing facility staff for their continuing support of this research. Research was sponsored by the Department of Energy (DOE) Office of Nuclear Energy, Advanced Fuel Campaign of the Fuel Cycle R\&D program. Neutron irradiation of FeCrAl alloys at ORNL's HFIR user facility was sponsored by the Scientific User Facilities Division, Office of Basic Energy Sciences, DOE. A portion of the support for one of the authors (SAB) was provided by the DOE Office of Nuclear Energy University Programs. The authors would like to thank Dr.

Maxim N. Gussev for his review and detailed insights on this manuscript.

\section{References}

[1] Fourth Annual Report - High-Temperature Materials and Reactor Component Development Programs, GEMP-334A. (1965).

[2] High-Temperature Materials Program Progress Report No. 55, Part A, GEMP-55A. (1966).

[3] High-Temperature Materials Program Progess Report No. 59, Part A, GEMP-59A. (1966).

[4] M. Kangilaski, The Effects of Neutron Radiation on Structural Materials, REIC Rep. No. 45. (1967).

[5] ORNL, Annual Progress Report for Period Ending June 30, 1966, Matels Ceram. Div. ORNL3970. (1996).

[6] F.G. Wilson, B.R. Knott, C.D. Desforges, Preparation and properties of some ODS Fe-Cr-Al alloys, Metall. Trans. A. 9 (1978) 275-282. doi:10.1007/BF02646711.

[7] K.A. Terrani, S.J. Zinkle, L.L. Snead, Advanced oxidation-resistant iron-based alloys for LWR fuel cladding, J. Nucl. Mater. 448 (2013) 420-435. doi:10.1016/j.jnucmat.2013.06.041.

[8] S.J. Zinkle, K.A. Terrani, J.C. Gehin, L.J. Ott, L.L. Snead, Accident tolerant fuels for LWRs: A perspective, J. Nucl. Mater. 448 (2014) 374-379. doi:10.1016/j.jnucmat.2013.12.005.

[9] B.A. Pint, K.A. Terrani, Y. Yamamoto, L.L. Snead, Material Selection for Accident Tolerant Fuel Cladding, Metall. Mater. Trans. E. 2 (2015) 190-196.

[10] B.A. Pint, K.A. Terrani, M.P. Brady, T. Cheng, J.R. Keiser, High temperature oxidation of fuel cladding candidate materials in steam-hydrogen environments, J. Nucl. Mater. 440 (2013) 420 427. doi:10.1016/j.jnucmat.2013.05.047.

[11] B.A. Pint, K.A. Unocic, K.A. Terrani, The effect of steam on the high temperature oxidation behavior of alumina-forming alloys, Mater. High Temp. 32 (2014) 28-35.

[12] Y. Yamamoto, B.A. Pint, K.A. Terrani, K.G. Field, Y. Yang, L.L. Snead, Development and 
property evaluation of nuclear grade wrought $\mathrm{FeCrAl}$ fuel cladding for light water reactors, J. Nucl. Mater. 467 (2015) 703-716. doi:10.1016/j.jnucmat.2015.10.019.

[13] K.G. Field, X. Hu, K.C. Littrell, Y. Yamamoto, L.L. Snead, Radiation tolerance of neutronirradiated model Fe-Cr-Al alloys, J. Nucl. Mater. 465 (2015) 746-755. doi:10.1016/j.jnucmat.2015.06.023.

[14] P. Ahmedabadi, G. Was, Stress corrosion cracking of ferritic-maretensitic steels in simulated boiling water reactor environment, Corrosion. In-Press (2015) 66-77. doi:10.5006/1806.

[15] Y. Yamamoto, Development and Quality Assessments of Commercial Heat Production of ATF FeCrAl Tubes, 2015.

[16] P.D. Edmondson, S.A. Briggs, Y.Yamamoto, R.H. Howard, K. Sridharan, K.A. Terrani, et al., Irradiation-enhanced $\alpha^{\prime}$ precipitation in model FeCrAl alloys, Scr. Mater. 116 (2016) 112-116. doi:10.1016/j.scriptamat.2016.02.002.

[17] S.A. Briggs, P.D. Edmondson, Y. Yamamoto, C. Littrell, R.H. Howard, C.R. Daily, et al., A combined APT and SANS investigation of alpha prime phase precipitation in neutron-irradiated model FeCrAl alloys, Submitt. to Acta Mater. (2016).

[18] A.A. Campbell, W.D. Porter, Y. Katoh, L.L. Snead, Method for analyzing passive silicon carbide thermometry with a continuous dilatometer to determine irradiation temperature, Nucl. Instruments Methods Phys. Res. Sect. B Beam Interact. with Mater. Atoms. 370 (2016) 49-58. doi:10.1016/j.nimb.2016.01.005.

[19] E.A. Little, D.A. Stow, Void-swelling in irons and ferritic steels, J. Nucl. Mater. 87 (1979) 25-39.

[20] J.-C. Brachet, X. Averty, P. Lamagnère, A. Alamo, F. Rozenblum, O. Raquet, et al., Behavior of Different Austenitic Stainless Steels, Conventional, Reduced Activation (RA) and ODS Chromium-Rich Ferritic-Martensitic Steels Under Neutron Irradiation at $325^{\circ} \mathrm{C}$ in PWR Environment, in: Eff. Radiat. Mater. 20th Int. Symp., ASTM International, 100 Barr Harbor Drive, PO Box C700, West Conshohocken, PA 19428-2959, 2001: pp. 500-500-21. doi:10.1520/STP10553S.

[21] M.N. Gussev, J.T. Busby, K.G. Field, M.A. Sokolov, S.E. Gray, Role of Scale Factor During Tensile Testing of Small Specimens, (2014) 1-19. doi:10.1520/stp157620140013.

[22] T. Byun, J. Kim, S. Chi, J. Hong, Effect of Specimen Thickness on the Tensile Deformation Properties of SA508 Cl.3 Reactor Pressure Vessel Steel, in: Small Specim. Test Tech., ASTM International, 100 Barr Harbor Drive, PO Box C700, West Conshohocken, PA 19428-2959, 1998: pp. 575-575-13. doi:10.1520/STP38013S.

[23] A. Guria, I. Charit, Observation of serrated flow in $\mathrm{APMT}^{\mathrm{TM}}$ steel, Mater. Lett. 160 (2015) 55-57. doi:10.1016/j.matlet.2015.07.072.

[24] A. Guria, I. Charit, Tensile properties of accident-tolerant aluminum-bearing ferritic steels, Ann. Nucl. Energy. (2016). doi:10.1016/j.anucene.2016.09.018.

[25] O. Anderoglu, T.S. Byun, M. Toloczko, S.A. Maloy, Mechanical Performance of Ferritic Martensitic Steels for High Dose Applications in Advanced Nuclear Reactors, Metall. Mater. Trans. A. 44 (2013) 70-83. doi:10.1007/s11661-012-1565-y.

[26] F. Bergner, C. Pareige, M. Hernández-Mayoral, L. Malerba, C. Heintze, Application of a threefeature dispersed-barrier hardening model to neutron-irradiated $\mathrm{Fe}-\mathrm{Cr}$ model alloys, J. Nucl. Mater. 448 (2014) 96-102. doi:10.1016/j.jnucmat.2014.01.024.

[27] W.-Y. Chen, Y. Miao, J. Gan, M.A. Okuniewski, S.A. Maloy, J.F. Stubbins, Neutron irradiation effects in Fe and $\mathrm{Fe}-\mathrm{Cr}$ at $300{ }^{\circ} \mathrm{C}$, Acta Mater. 111 (2016) 407-416. 
doi:10.1016/j.actamat.2016.03.060.

[28] M.-H. Mathon, Y. De Carlan, X. Averty, A. Alamo, C.-H. De Novion, Small Angle Neutron Scattering Study of Irradiated Martensitic Steels: Relation Between Microstructural Evolution and Hardening, J. ASTM Int. 2 (2005). www.astm.org (accessed August 26, 2016).

[29] K.-H. Park, J.C. LaSalle, L.H. Schwartz, M. Kato, Mechanical properties of spinodally decomposed Fe-30 wt\% Cr alloys: Yield strength and aging embrittlement, Acta Metall. 34 (1986) 1853-1865. doi:10.1016/0001-6160(86)90130-6.

[30] A. Triki, F. Bley, Y. Brechet, F. Louchet, On the origin of hardening in aged FeCr alloys: relation between unmixing and mechanical properties, in: U. Messerschmidt, F. Appel, J. Heydenreich, V. Schmidt (Eds.), Electron Microsc. Plast. Fract. Res. Mater., Akademie-Verlag, Berlin, 1989: pp. 139-147.

[31] K. Wang, Y. Dai, P. Spätig, Microstructure and fracture behavior of F82H steel under different irradiation and tensile test conditions, J. Nucl. Mater. 468 (2016) 246-254. doi:10.1016/j.jnucmat.2015.09.031.

[32] E.A. Little, Void-swelling in irons and ferritic steels: I. Mechanisms of swelling suppression, J. Nucl. Mater. 87 (1979) 11-24. doi:10.1016/0022-3115(79)90122-3.

[33] K. Linga Murty, Interstitial-Impurity Radiation-Defect Interactions in Ferritic Steels, JOM. 37 (1985) 34-39. doi:10.1007/BF03258766.

[34] M.S. Wechsler, K.L. Murty, Impurity-Defect Interactions and Radiation Hardening and Embrittlement in BCC Metals, Metall. Trans. A. 20 (1989) 2637-2649. doi:10.1007/BF02670157.

[35] I.S. Kim, S.S. Kang, Dynamic strain aging in SA508-class 3 pressure vessel steel, Int. J. Press. Vessel. Pip. 62 (1995) 123-129. doi:10.1016/0308-0161(95)93969-C.

[36] K.. Kim, J.. Kim, J.. Suk, U.. Sung, H.. Kwon, Influences of the dynamic strain aging on the J-R fracture characteristics of the ferritic steels for reactor coolant piping system, Nucl. Eng. Des. 228 (2004) 151-159. doi:10.1016/j.nucengdes.2003.06.014.

[37] B. V Cockeram, R.W. Smith, K.J. Leonard, T.S. Byun, L.L. Snead, Development of microstructure and irradiation hardening of Zircaloy during low dose neutron irradiation at nominally $358^{\circ} \mathrm{C}$, J. Nucl. Mater. 418 (2011) 46-61. doi:10.1016/j.jnucmat.2011.07.006.

[38] R.B. Rebak, Alloy Selection for Accident Tolerant Fuel Cladding in Commercial Light Water Reactors, Metall. Mater. Trans. E. (2015). doi:10.1007/s40553-015-0057-6.

[39] K.A. Terrani, B.A. Pint, Y.-J. Kim, K.A. Unocic, Y. Yang, C.M. Silva, et al., Uniform corrosion of FeCrAl alloys in LWR coolant environments, J. Nucl. Mater. 479 (2016) 36-47. doi:10.1016/j.jnucmat.2016.06.047.

Tables 
Table 1: Summary of FeCrAl alloy compositions (in wt \%) used in this study

\begin{tabular}{|l|c|c|c|c|c|c|c|c|c|c|}
\hline \multirow{2}{*}{ ID } & \multicolumn{10}{|c|}{ Composition (wt \%) } \\
\cline { 2 - 12 } & $\mathbf{F e}$ & $\mathbf{C r}$ & $\mathbf{A l}$ & $\mathbf{Y}$ & $\mathbf{C}$ & $\mathbf{S}$ & $\mathbf{O}$ & $\mathbf{N}$ & $\mathbf{P}$ & $\mathbf{S i}$ \\
\hline F1C5AY & 85.15 & 10.01 & 4.78 & 0.038 & 0.005 & 0.0010 & 0.0013 & 0.0003 & 0.006 & $<0.01$ \\
\hline B125Y & 83.56 & 11.96 & 4.42 & 0.027 & 0.005 & 0.0013 & 0.0017 & 0.0009 & 0.0 & 0.01 \\
\hline B154Y-2 & 80.99 & 15.03 & 3.92 & 0.035 & 0.005 & 0.0004 & 0.0025 & 0.0007 & $<0.002$ & 0.01 \\
\hline B183Y-2 & 79.52 & 17.51 & 2.93 & 0.017 & 0.005 & 0.0006 & 0.0015 & 0.0011 & $<0.002$ & $<0.01$ \\
\hline $\begin{array}{l}\text { Kanthal } \\
\text { APMT }\end{array}$ & 69.01 & 21.64 & 4.93 & 0.120 & 0.03 & $<0.001$ & 0.494 & 0.0504 & 0.01 & $<0.001$ \\
\hline
\end{tabular}

${ }^{1}$ Addtional elements: Mo: 2.77, Co: 0.02, Cu: 0.04, Hf: 0.16, Mn: 0.1, Nb: 0.02, Ni: 0.12, Ti: 0.02, V: 0.04, Zr: 0.1; all in wt \%.

Table 2: Summary of FeCrAl alloy irradiation conditions

\begin{tabular}{|c|c|c|c|c|c|c|}
\hline Capsule ID & $\begin{array}{c}\text { Exposure } \\
\text { Time } \\
(\mathbf{h})\end{array}$ & $\begin{array}{c}\text { Neutron Flux } \\
\left(\mathbf{n} / \mathbf{c m}^{2} \mathbf{s}\right) \\
\mathbf{E}>\mathbf{0 . 1} \mathbf{~ M e V}\end{array}$ & $\begin{array}{c}\text { Neutron Fluence } \\
\left(\mathbf{n} / \mathbf{c m}^{\mathbf{2}}\right) \\
\mathbf{E}>\mathbf{0 . 1} \mathbf{M e V}\end{array}$ & $\begin{array}{c}\text { Dose Rate } \\
(\mathbf{d p a} / \mathbf{s})\end{array}$ & $\begin{array}{c}\text { Dose } \\
(\mathbf{d p a})\end{array}$ & $\begin{array}{c}\text { Irradiation } \\
\text { Temperature } \\
\left({ }^{\circ} \mathbf{C}\right)\end{array}$ \\
\hline FCAY-01 $^{1}$ & 120 & $8.54 \times 10^{14}$ & $3.69 \times 10^{20}$ & $7.7 \times 10^{-7}$ & 0.3 & $334.5 \pm 0.6$ \\
\hline FCAY-02 & 301 & $8.54 \times 10^{14}$ & $9.25 \times 10^{20}$ & $7.7 \times 10^{-7}$ & 0.8 & $355.1 \pm 3.4$ \\
\hline FCAY-03 & 614 & $8.84 \times 10^{14}$ & $1.95 \times 10^{21}$ & $8.1 \times 10^{-7}$ & 1.8 & $381.9 \pm 5.4$ \\
\hline FCAY-04 & 2456 & $8.74 \times 10^{14}$ & $7.73 \times 10^{21}$ & $7.9 \times 10^{-7}$ & 7.0 & $319.9 \pm 12.7$ \\
\hline FCAY-05 & 4914 & $8.74 \times 10^{14}$ & $1.55 \times 10^{22}$ & $7.8 \times 10^{-7}$ & 13.8 & $340.5 \pm 25.7$ \\
\hline
\end{tabular}

${ }^{\mathrm{I}} \mathrm{F} 1 \mathrm{C} 5 \mathrm{AY}$ and B183Y-2 were not contained within this capsule.

${ }^{2} \mathrm{~B} 125 \mathrm{Y}$ and B154Y-2 were not contained within this capsule.

Figures 


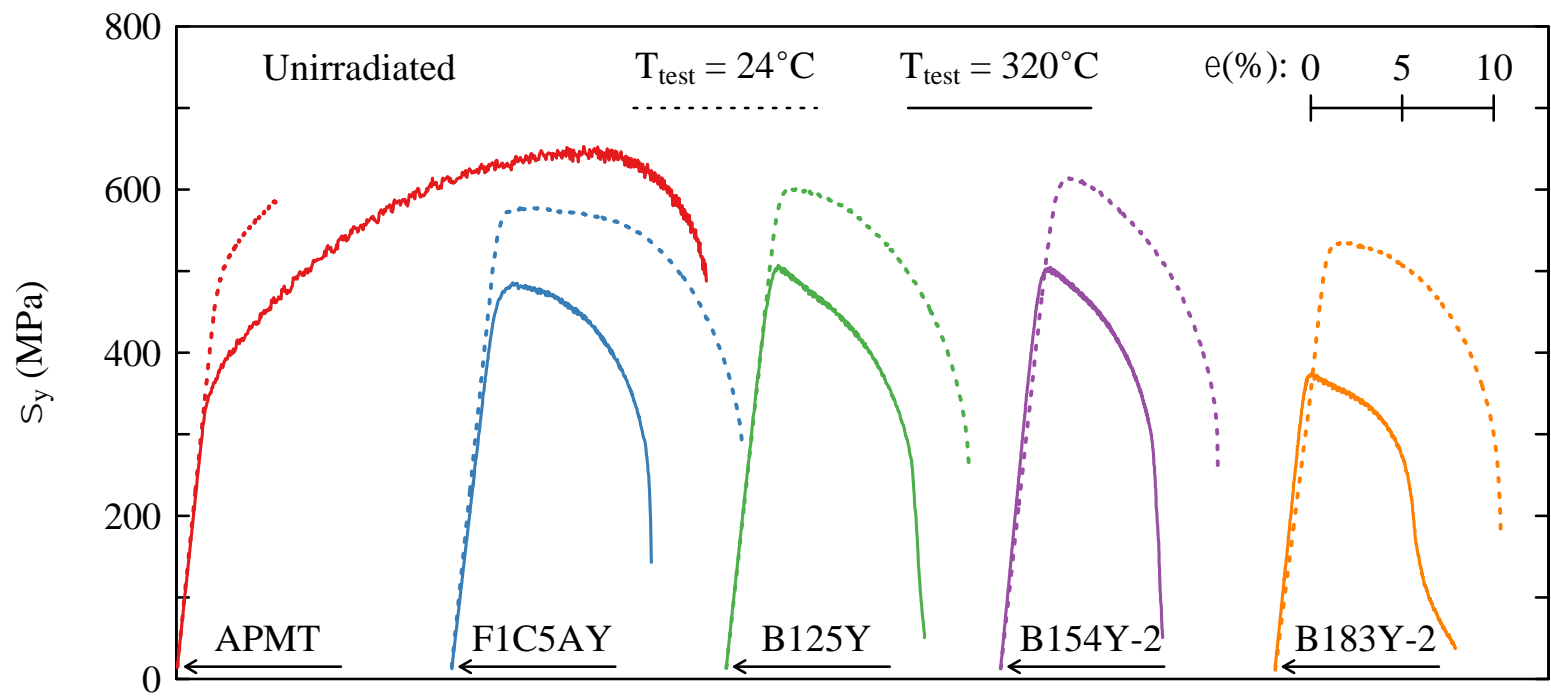

Figure 1: Plots showing stress-strain curves for Kanthal APMT and model FeCrAl alloys in the unirradiated condition (dashed lines: tested at room temperature $\left(\mathrm{T}_{\text {test }}=\mathbf{2 4}{ }^{\circ} \mathrm{C}\right)$; solid lines: tested at elevated temperature $\left(\mathrm{T}_{\text {test }}=320^{\circ} \mathrm{C}\right)$ ). 
(a)

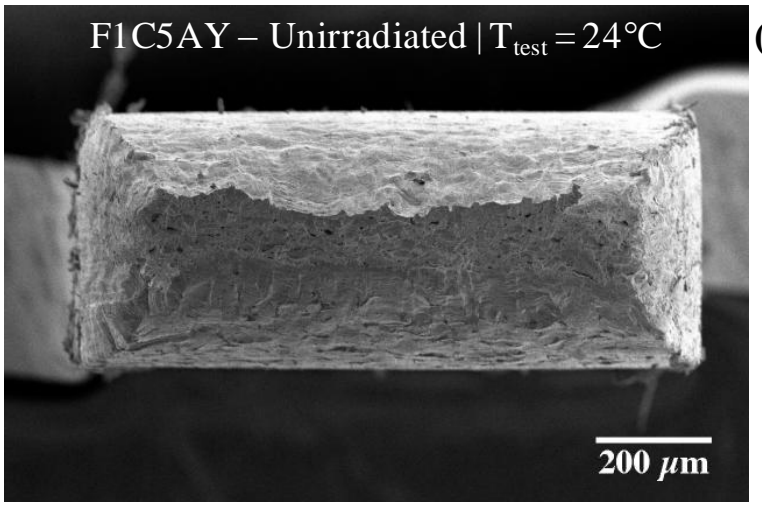

(c)

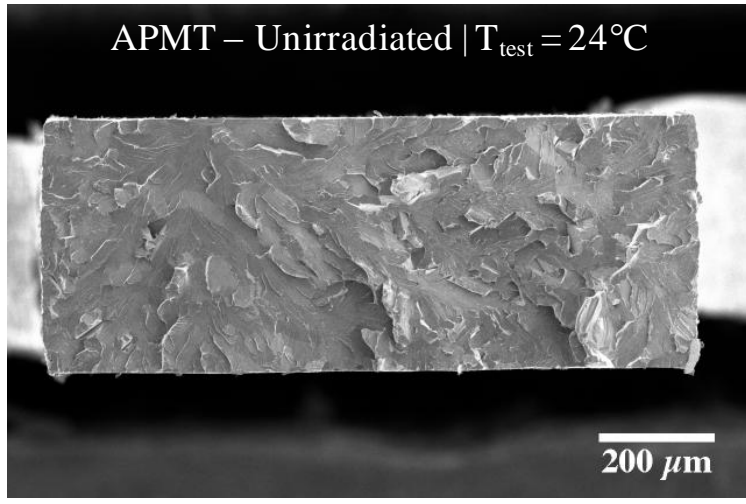

(b)

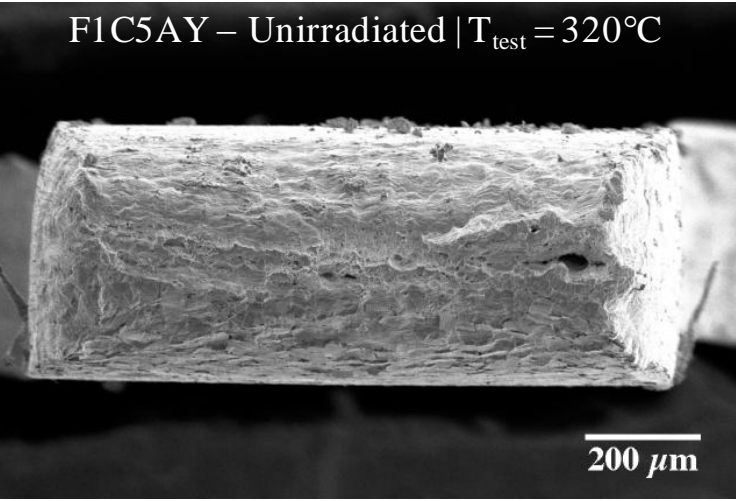

(d)

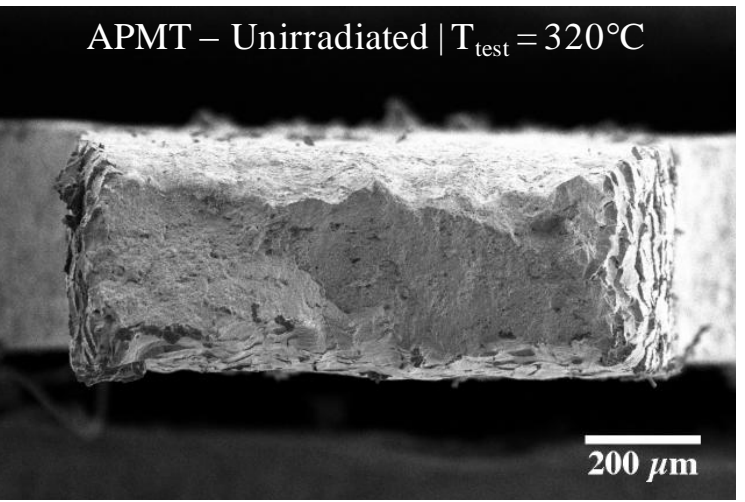

Figure 2: SEM micrographs showing the fracture surfaces after tensile testing in the unirradiated condition for (a) F1C5AY model FeCrAl alloy tested at room temperature $\left(\mathrm{T}_{\text {test }}=24^{\circ} \mathrm{C}\right)$; (b) F1C5AY model FeCrAl alloy tested at elevated temperature $\left(\mathrm{T}_{\text {test }}=320^{\circ} \mathrm{C}\right)$; $(\mathrm{c})$ Kanthal APMT tested at room temperature $\left(\mathrm{T}_{\text {test }}=24^{\circ} \mathrm{C}\right)$; $(\mathrm{d})$ Kanthal APMT tested at elevated temperature $\left(\mathbf{T}_{\text {test }}=320^{\circ} \mathbf{C}\right)$. 

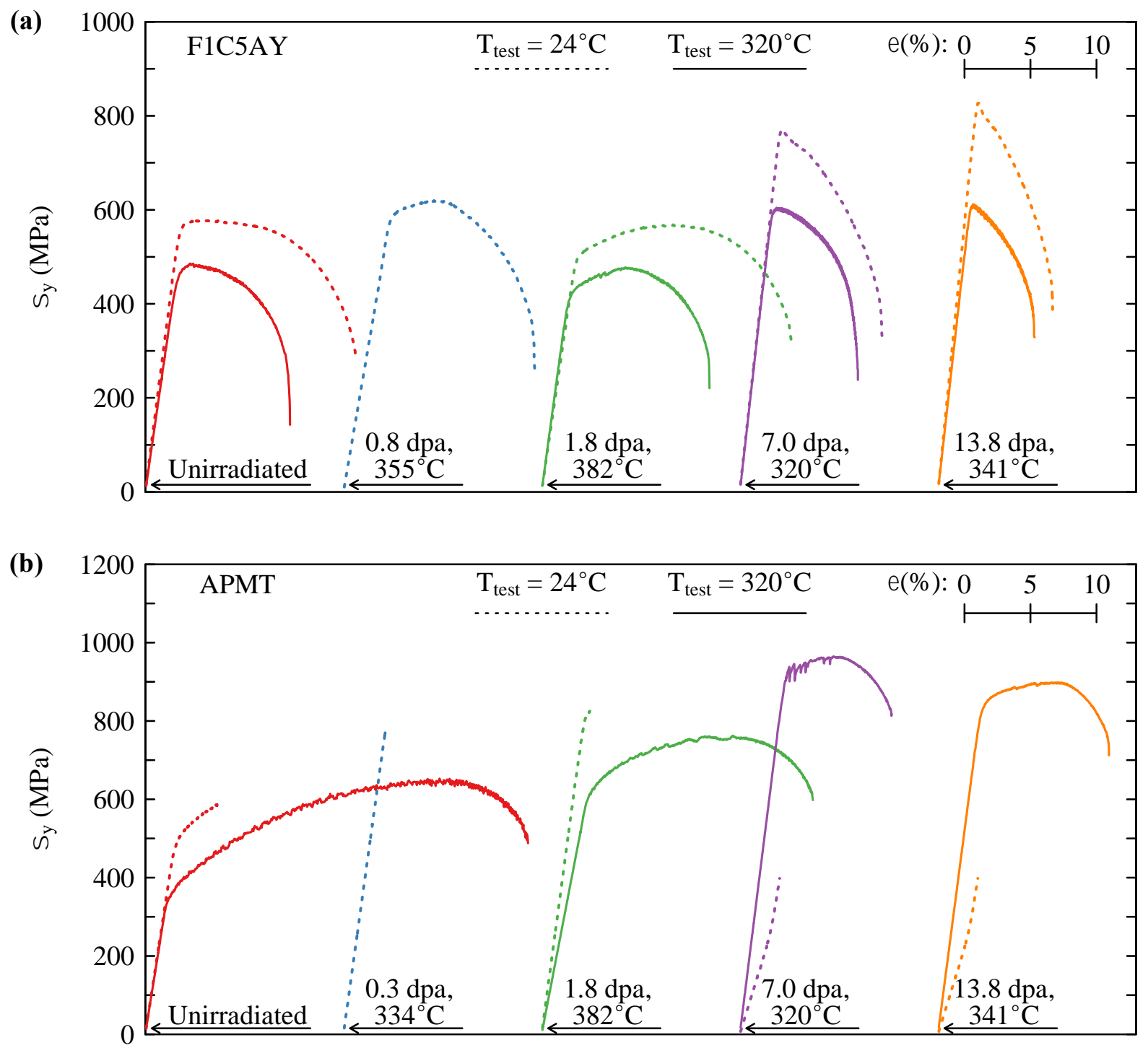

Figure 3: Plots showing stress-strain curves after neutron irradiation for (a) F1C5AY model FeCrAl alloy and (b) Kanthal APMT alloy. (Dashed lines: tested at room temperature $\left(\mathrm{T}_{\text {test }}=24^{\circ} \mathrm{C}\right)$; solid lines: tested at elevated temperature $\left(T_{\text {test }}=320^{\circ} \mathrm{C}\right)$ ). Tensile tests at $320^{\circ} \mathrm{C}$ were not performed in the 0.3 or 0.8 dpa condition. 

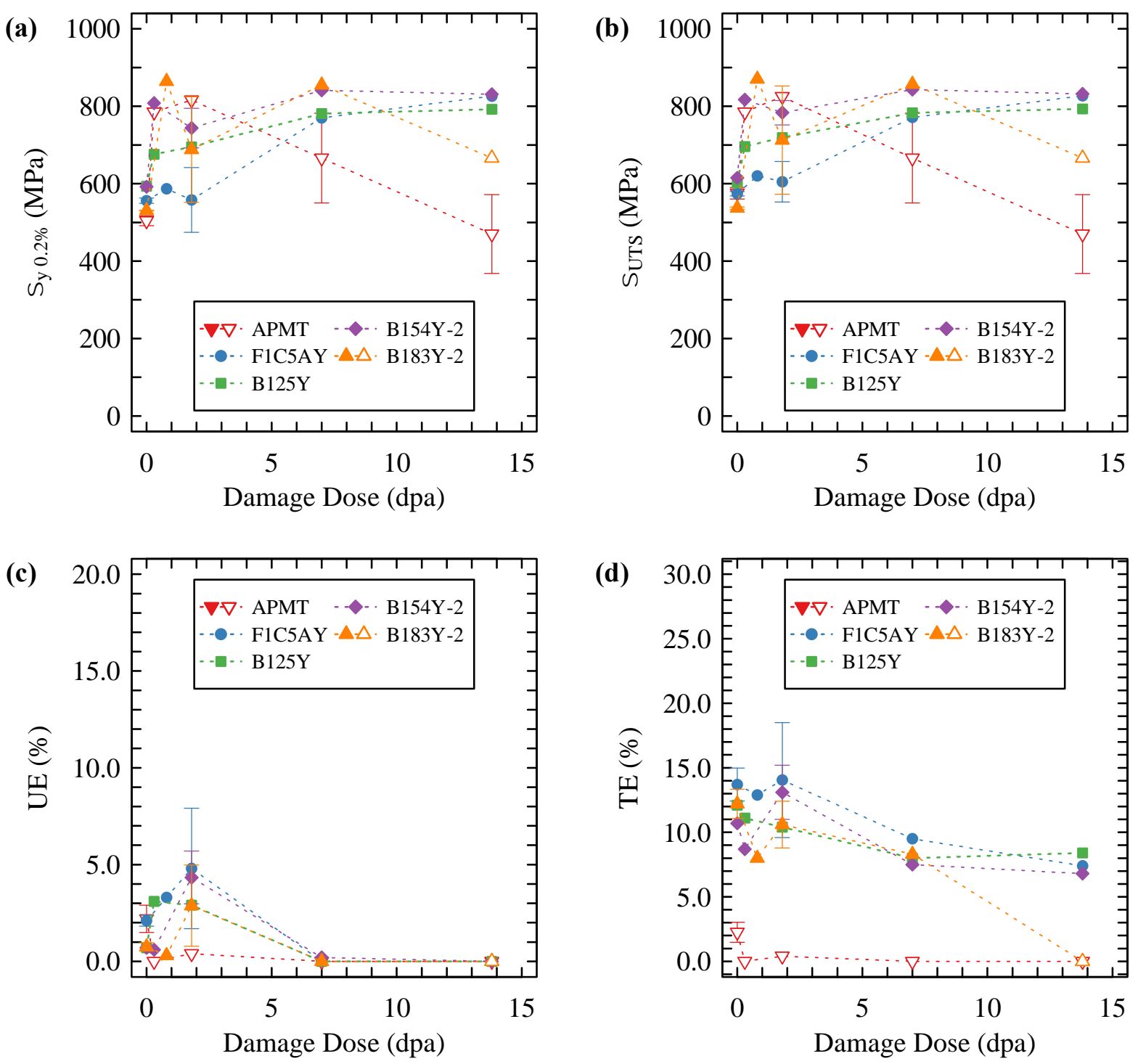

Figure 4: Comparison of Kanthal APMT and model FeCrAl alloys' tensile response as a function of dose (dpa) for tensile tests performed at room temperature $\left(T_{\text {test }}=24^{\circ} \mathrm{C}\right)$. Open symbols for APMT and B183Y -2 represent tests that failed in a brittle manner. $\sigma_{y 0.2 \%}: 0.2 \%$ offset yield strength;

$\sigma_{U T S}$ : ultimate tensile strength; UE: uniform elongation; TE: total elongation. 

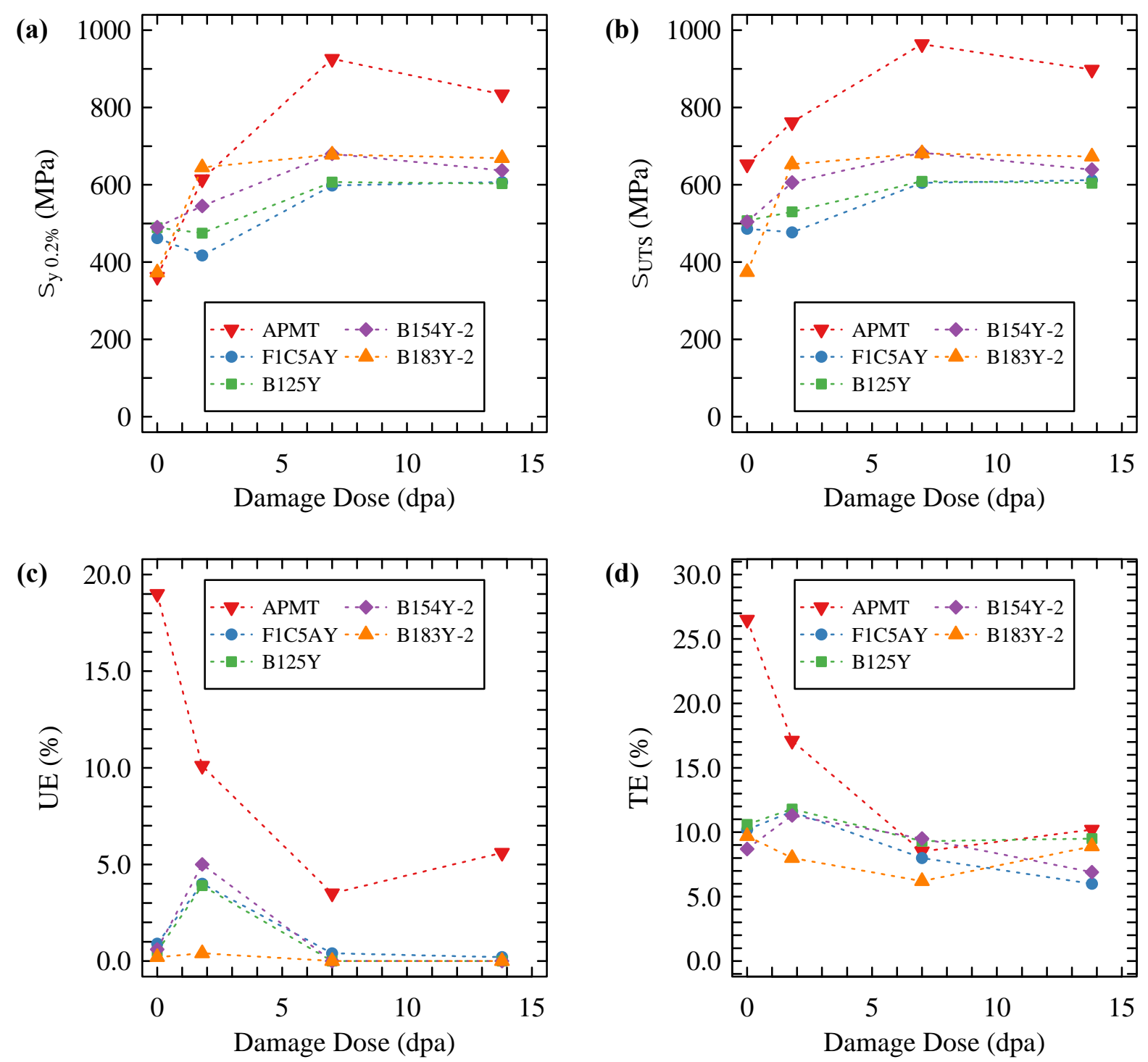

Figure 5: Comparison of Kanthal APMT and model FeCrAl alloys' tensile response as a function of dose (dpa) for tensile tests performed at elevated temperature $\left(\mathrm{T}_{\text {test }}=320^{\circ} \mathrm{C}\right), \sigma_{y \mathbf{0 . 2} \%}: 0.2 \%$ offset yield strength; $\sigma_{U T S}$ : ultimate tensile strength; UE: uniform elongation; TE: total elongation. 
(a)

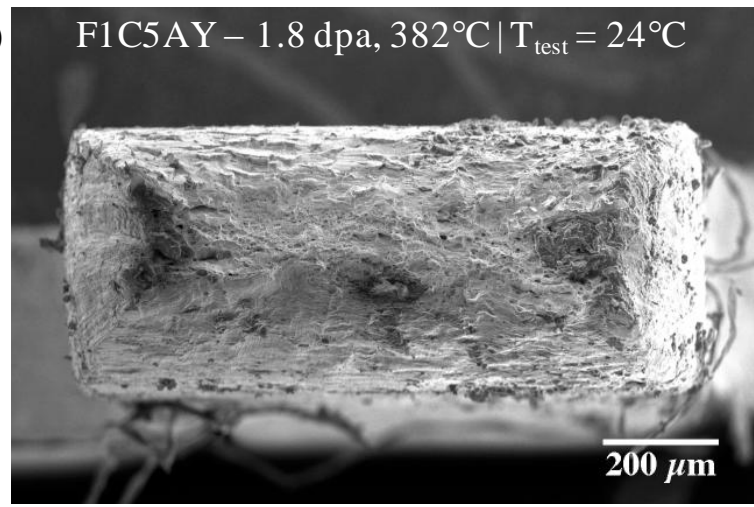

(c)

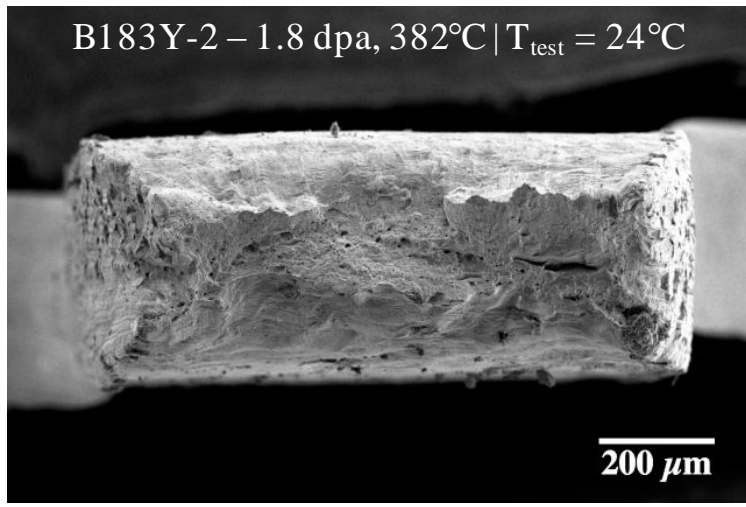

(e)

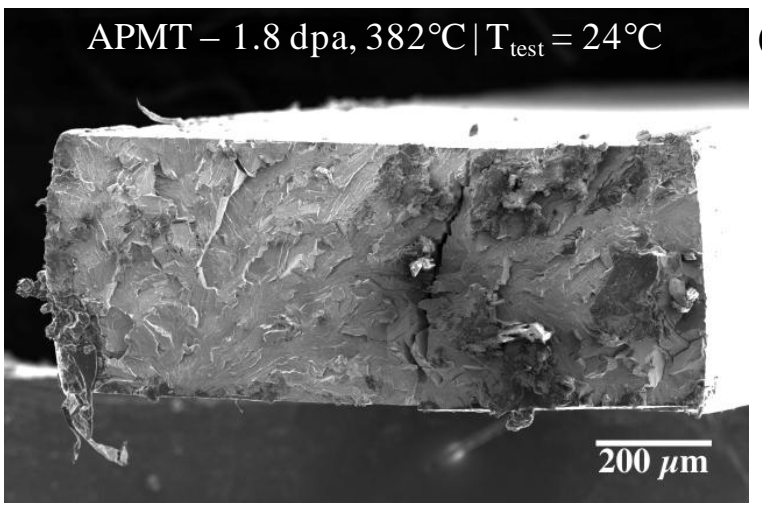

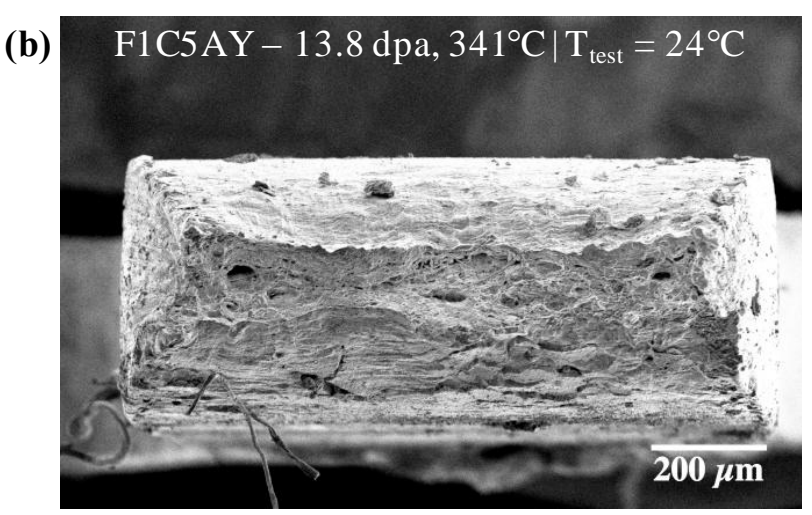

(d)

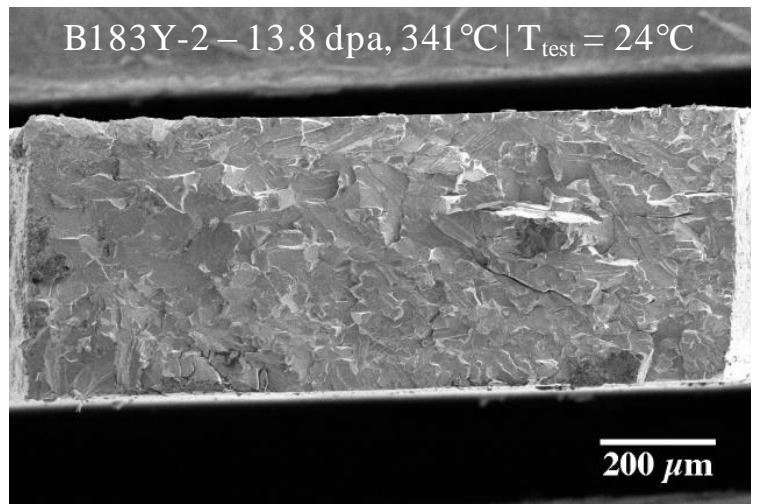

(f)

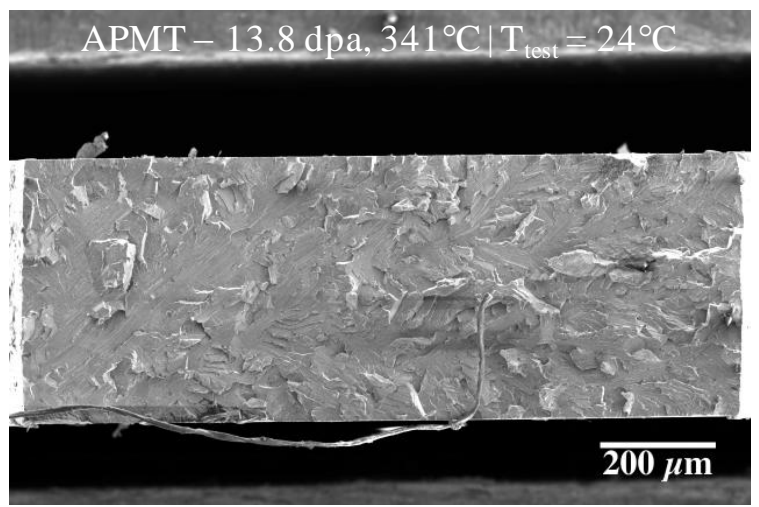

Figure 6: SEM micrographs showing the fracture surfaces after tensile testing at room temperature $\left(\mathrm{T}_{\text {test }}=24^{\circ} \mathrm{C}\right.$ ). (a-b) F1C5AY; (c-d) B183Y-2; (e-f) Kanthal APMT. (a,c,e) Alloys irradiated to 1.8 dpa at $382^{\circ} \mathrm{C}$; and $(b, d, f)$ alloys irradiated to 13.8 dpa at $341^{\circ} \mathrm{C}$. 
(a)
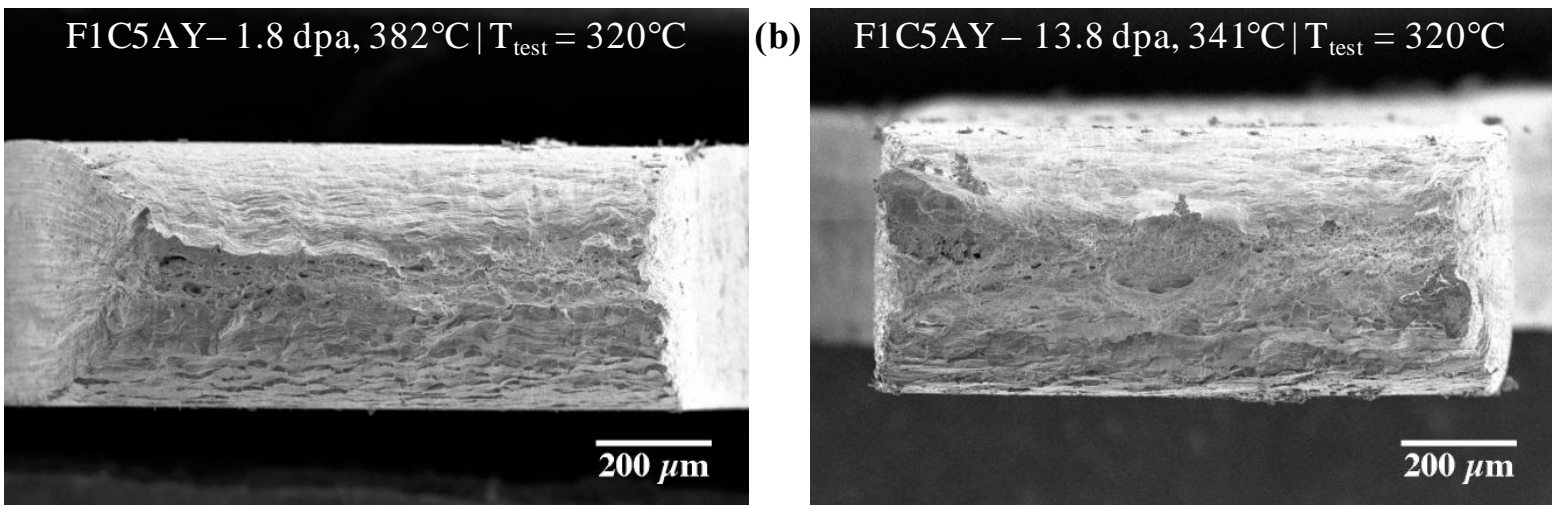

(c)
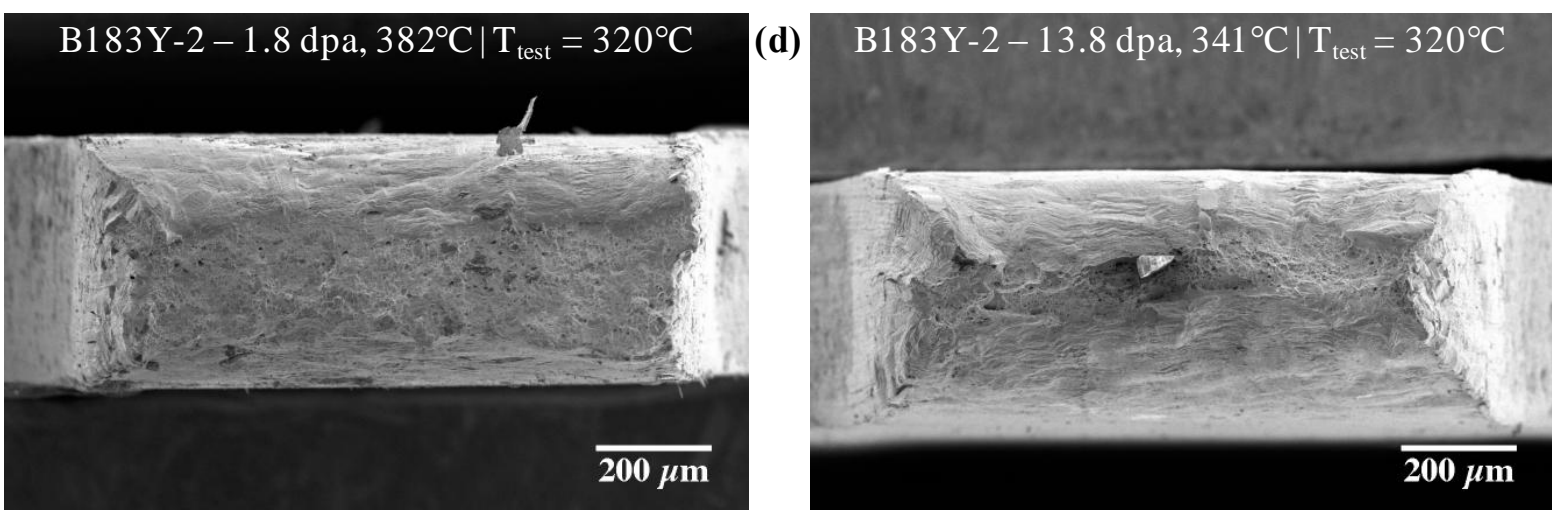

(e)
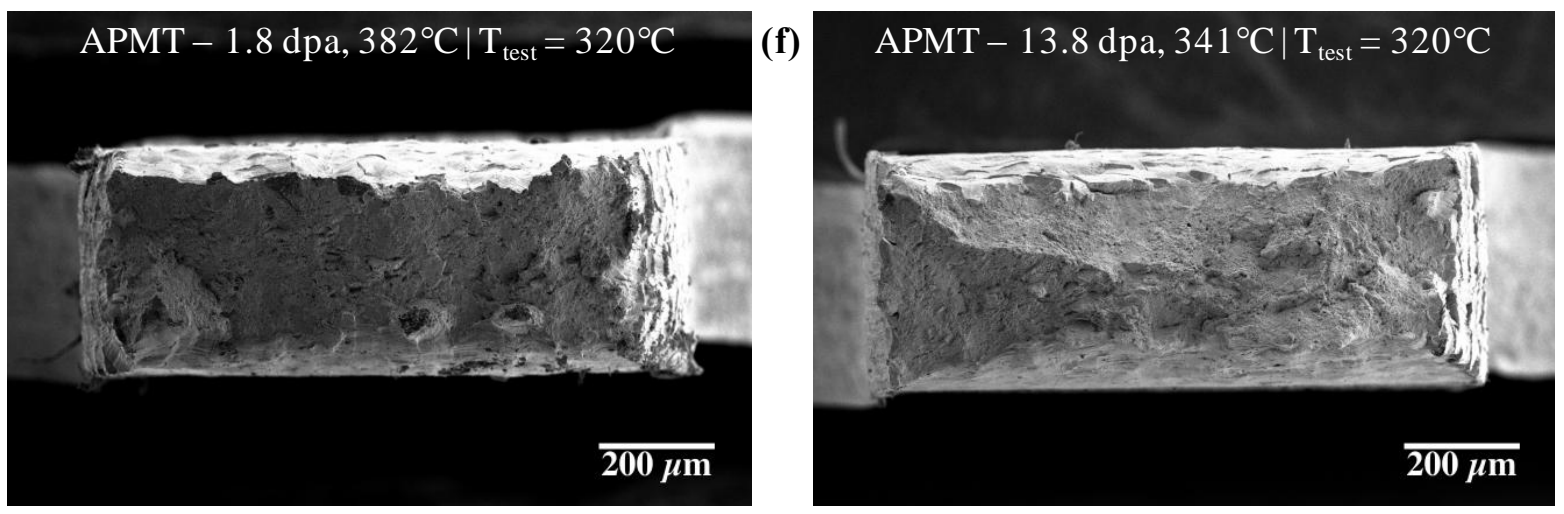

Figure 7: SEM micrographs showing the fracture surfaces after tensile testing at elevated temperature $\left(\mathrm{T}_{\text {test }}=320^{\circ} \mathrm{C}\right)$. (a-b) F1C5AY; (c-d) B183Y-2; (e-f) Kanthal APMT. (a,c,e) Alloys irradiated to $1.8 \mathrm{dpa}$ at $382^{\circ} \mathrm{C}$; and $(\mathrm{b}, \mathrm{d}, \mathrm{f})$ alloys irradiated to $13.8 \mathrm{dpa}$ at $341^{\circ} \mathrm{C}$. 

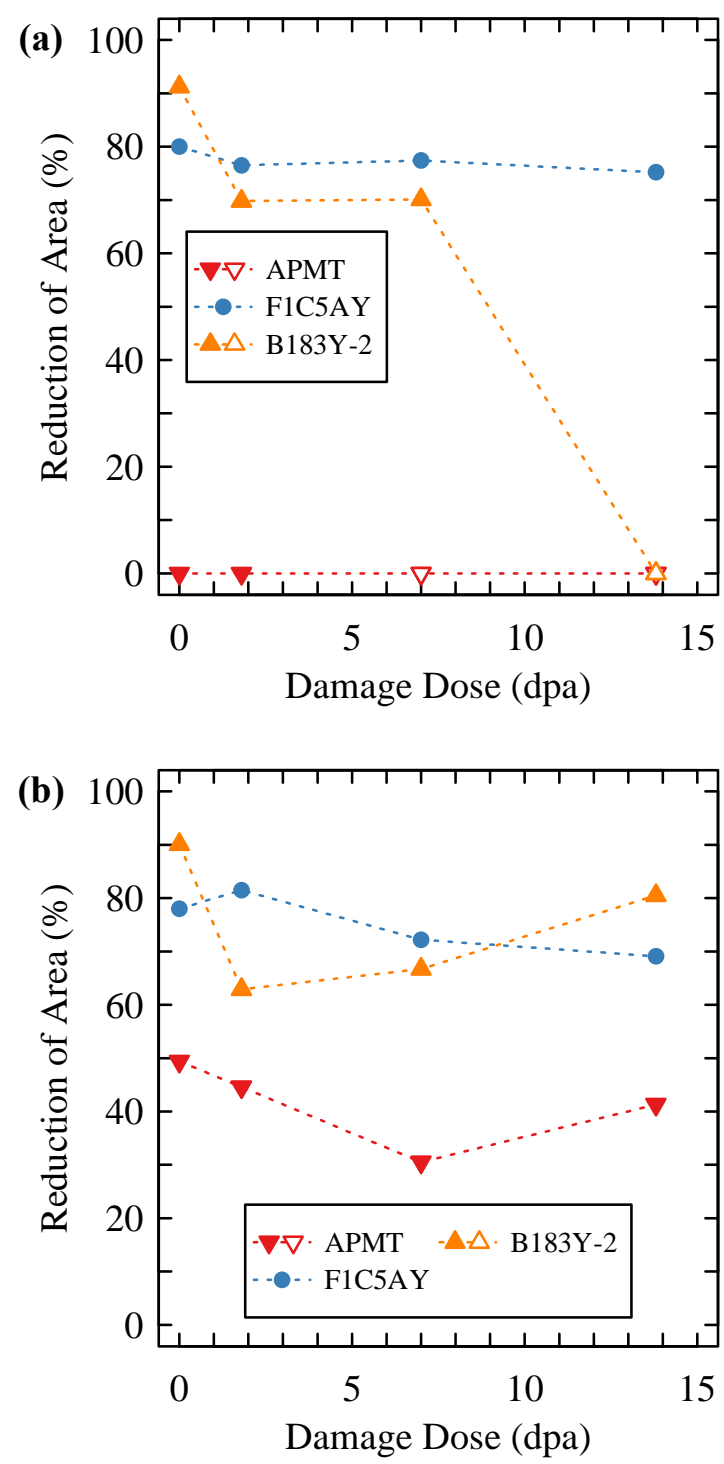

Figure 8: Reduction of areas of selected Kanthal APMT and model FeCrAl alloys as a function of dose (dpa) for tensile tests performed at (a) room temperature $\left(\mathrm{T}_{\text {test }}=\mathbf{2 4}{ }^{\circ} \mathrm{C}\right.$ ) and (b) elevated temperature $\left(\mathrm{T}_{\text {test }}=320^{\circ} \mathrm{C}\right)$. Open symbols for APMT and B183Y-2 represent tests that failed in a brittle manner. 

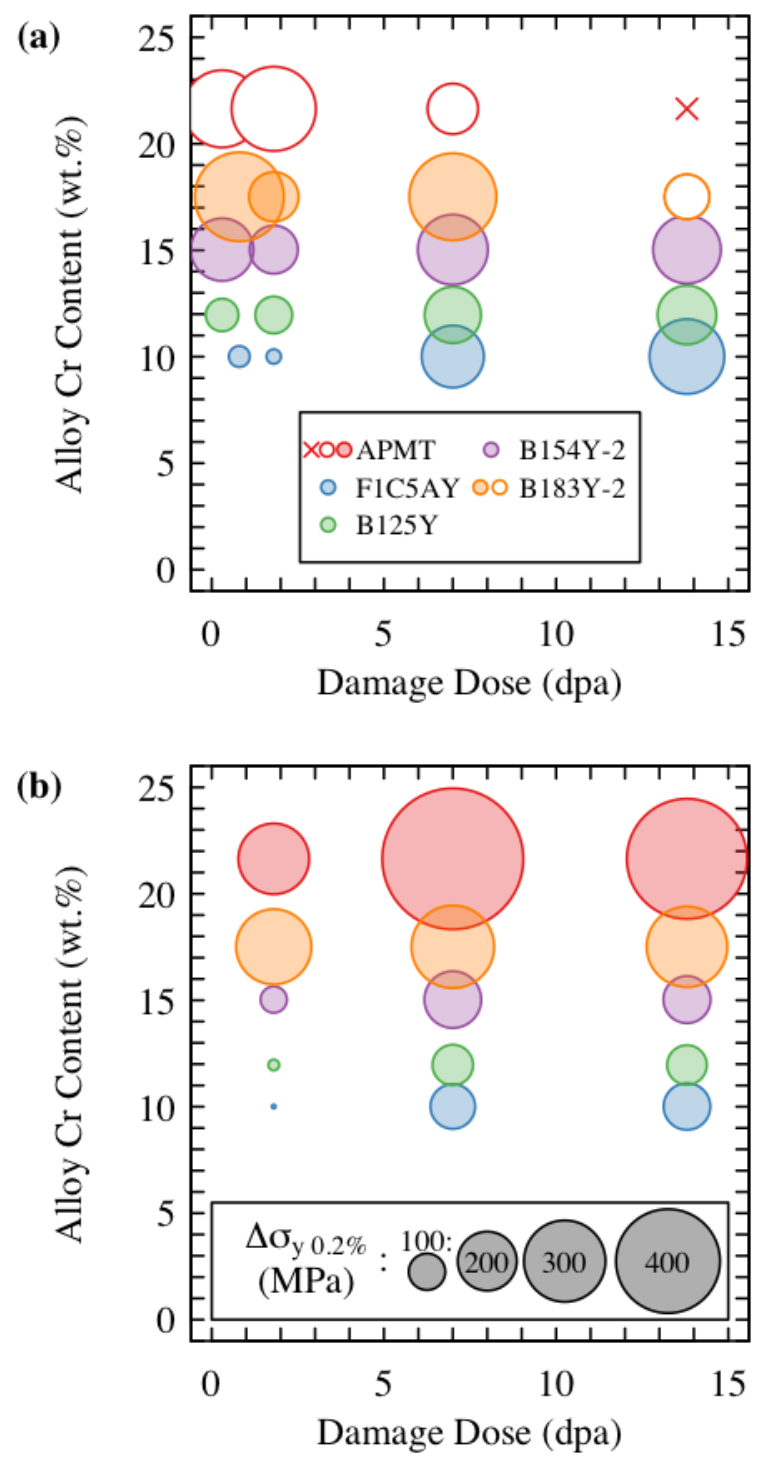

Figure 9: Bubble plot indicating change in $0.2 \%$ offset yield strength $\left(\Delta \sigma_{y 0.2 \%}\right)$ as a function of damage dose (dpa) and alloy $\mathrm{Cr}$ content for tensile tests performed at (a) room temperature $\left(T_{\text {test }}=24^{\circ} \mathrm{C}\right)$ and $(\mathrm{b})$ elevated temperature $\left(\mathrm{T}_{\text {test }}=320^{\circ} \mathrm{C}\right)$. Open symbols for APMT and B183Y-2 represent tests that failed in a brittle manner. Symbol " $x$ " represents data points where the brittle failure stress occurred below the unirradiated yield stress. Legends in (a) and (b) are valid for both plots. 


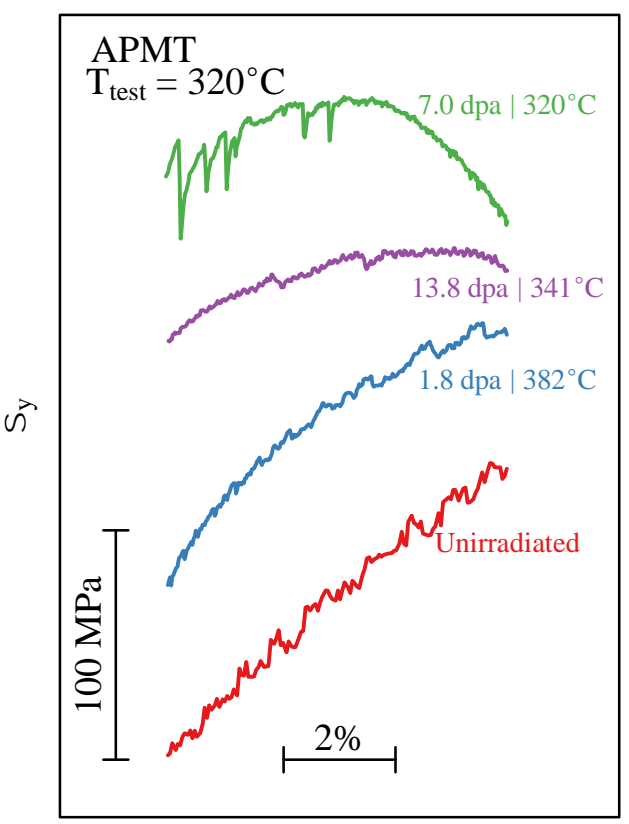

Figure 10: Segments of engineering stress-strain curves showing serrated flow for unirradiated and irradiated Kanthal APMT specimens when tested at elevated temperature $\left(\mathrm{T}_{\text {test }}=320^{\circ} \mathrm{C}\right)$. 